\title{
TENTATIVE INTERPRETATIONS IN PSYCHOTHERAPY
}

\author{
AH. CHAPMAN*, MIRIAM CHAPMAN-SAMTANA*
}

\begin{abstract}
SUMMARY - The nature and technique of the tentative interpretation are described. Its usefulness and advantages are outlined, and its field of application in psychotherapy is discussed.
\end{abstract}

KE YWORD S : psychotherapy, tentative interpretation, nature and technique, usefulness and advantages.

Interpretações tentativas em psicoterapia

RESUMO - A natureza e o método da interpretação tentativa são descritas. A sua utilidade e as suas vantagens são esboçadas e o seu uso em psicoterapia é examinado.

PALAVRAS-CHAVE: psicoterapia, interpretações tentativas, natureza e método, utilidade e vantagens.

The proper timing of interpretations is a major problem in psychotherapy ${ }^{1} \wedge^{5}$. A premature interpretation alarms or antagonizes a patient and an unduly delayed interpretation is an ineffective anticlimax; if the premature and late interpretations do not have these effects, they merely fall flat and the patient is unable to assimilate them meaningfully.

A correct interpretation is a piece of knowledge about the patient wich is made available to him by the therapist at a time when he can accept it and incorporate it into his emotional life and relationship with people. This piece of information may vary much in content. It may for instance be about his feeling toward an important person in his life, or it may deal with some general pattern of his behavior, or it may be about a persistent digression he is making in talking about relevant, significant things. An interpretation may even be a sociological or cultural obsevation that has a pertinent bearing on the patient in his larger interpersonal setting. The interpretation is made in the clearest words the therapist can muster, but an accompanying tone of voice, or a gesture, or a facial expression is an integral part of it. It is these latter items that make an effective interpretation, and psychotherapy in general, an art rather than a science. An interpretation may sometimes take the form of a question; sometimes it is conveyed in a simile or a metaphor, at other times it may be merely an inarticulate murmur of disbelief or assent. In most cases, however, an interpretation is a forthright statement.

An interpretation is a creature of context and out of context it may have little impact or meaning. The context it exists in the patient's ongoing talk at the time, and that is always in the setting of the current patient-therapist relationship. The fact that an interpretation is a creature of context highlights the necessity for making it at the right time.

For some interpretations there is only one proper time, and that being lost returns no more. For example, the patient who stops in impatient irritation when the therapist coughs or uses some particular expression (thus imitating inadvertently a habit of the patient's father) may have this emotional reaction pointed out with effect then; five minutes later the same interpretation would

\footnotetext{
* From the Samur Hospital, Vitoria da Conquista, Bahia, Brazil. Aceite: 2-agosto-1993.
} 
fall flat, for the patient could no longer recall and recognize the disappeared anger of that moment. At other times repeated opportunities occur for the therapist to make an interpretation, perhaps over long periods of therapeutic time. But for most interpretations there is an optimum time, usually not long; this optimum time is surrounded on one or both sides by permissible time, and beyond this strech the barren, unprofitable wastes of premature and delayed interpretations. Interpretations, properly timed, expedite therapy and push it along; when poorly timed they slow it down or disrupt it. The patient must be able to assimilate an interpretation; a major interpretation is often preceded by lesser ones and is later consolidated by its application to a variety of interpersonal and emotional events and relationships. It must come at a time when it relates to mobilized feelings and significant interpersonal happenings or it will be merely an exercise in sterile words.

The concept of the tentative interpretation is a modification of Harry Stack Sullivan's principle of the consensual validation of hypotheses in psychotherapy ${ }^{113}$. A tentative interpretation is one which attempts to place at the disposal of the patient knowledge of himself which he pick up and begin to utilize at any time in which he is able to do so. This technique is as follows: the therapist, when he feels he has knowledge about the patient which the patient may be able to use, states this knowledge in the following words, "As we have been talking about your problem I have begun to form certain impressions about (some aspects of) your difficulty. My impressions cannot be stated with rigid certainty; they are, frankly, no more than tentative, or provisional, impressions, the validity of which you and I shall examine as we learn more about you. However, I think it worthwhile to point them out now. You may accept or reject them, both now and later; but as impressions I think they are worthy of our consideration. It seems to me that in your relationships with..." and then the interpretation is made.

To make a tentative interpretation is to make information available to a patient over a long period of time, constantly at his command; the patient determines the timing of its application. It also offers the possibility of gradual, perhaps bit by bit, assimilation of the interpretation; for example, it does not mobilize anxiety when information is given before the patient can accept it because its tentative quality does not require the patient to accept it or reject it out of hand. He may, so to speak, lay it on the table and look at it from time to time. Later, when further therapy enables him to see it in a different light he may pick it up, examine it and begin to incorporate it into his psychology and interpersonal life.

Moreover, when a premature interpretation (in this case not a tentative one) is given as a statement of imparted fact it may lead to an impasse between the patient and the therapist. When the patient rejects it the therapist is faced with three alternatives: a) He may restate it, or reapply it, in various ways and, despite himself, degenerate into arguing with the patient; effective therapy ends at this point, b) He may, validly or not, change his opinion about the patient's difficulties and his appropriateness for psychotherapy. For example, he may conclude that "the patient's resistances are greater than previously estimated", or that "his character structure is more rigid than it was heretofore thought to be", or that "his dynamics increasingly suggest a psychotic core, with desperate defenses around it". Such conclusions at times may become convenient refuges for the therapist, $\mathrm{c}$ ) He may accept the fact that the interpretation was premature and go to work to prepare the ground for it to be made again later, in the meantime working other veins of material. Obviously the third is the best course, but it requires a certain amount of humbleness in the therapist and the ability to recognize that he made a mistake. There is the danger in such cases that after a few such experiences the therapist may become overly cautious in his interpretations, and the effectiveness of treatment as a whole may accordingly be reduced.

The effects of a premature interpretation sometimes are not mitigated by a skillful retreat, as when the therapist says, "Perhaps this is something you cannot see clearly just now; in time certain aspects of it may become evident, however". The premature interpretation may have mobilized anxiety and this emotional pain may have brought in its train the defenses we conceptualize as repression , rationalization, denial and other forms of unhealthy reactions. III - timed premature 
interpretations, especially if they are pushed, may even cause the patient to stop treatment altogether. In less menacing instances, even the same area is later reapproached the new defenses are added barriers to work through.

A tentative interpretation obviates these dangers. The way is left open the patient to set it aside, but yet within reach until it can be examined comfortably or at least with minimal anxiousness. It is offered to him, not thrust at him; he can accept it in part or in full, or can table it for the time being. Thus a tentative interpretation rarely causes an impasse between therapist and patient. It has one further advantage; the therapist has no apparent proprietary interest in seeing that the patient eventually accepts it. There is no demand, overt or implied, that the patient accepts it.

The difficulty of a delayed, or postmature, interpretation rarely occurs when tentative interpretations are used since the therapist tends to offer tentative interpretations early rather than late, as hypotheses to be substantiated or not as treament progresses.

A tentative interpretation extends the range of time when the patient may grasp and use information into periods between interviews and even after therapy has stopped. It makes knowledge of himself continually available without alarming or upsetting him, or without causing him to flee from it, or without causing him to erect barricades against it. It is, in our experience, the interpretative technique of choice in most instances.

What are the possible disadvantages of this technique? It may be objected that to put an interpretation in this provisional way adulterates it and robs it of much of its impact and hence effectiveness. We have not found this to be so. Patients seem rather to value the openness and flexibility of the therapist about his interpretations. Moreover, the tentative nature of the interpretation, as a hypothesis to be confirmed or not by further exploration of the patient's life, is, we feel, more in keeping with the facts in most therapeutic situations. Every therapist has more than once found that his previous concepts about a patient had to be revised or abandoned in the light of further knowledge about him. This ever present possibility of human error gives every interpretation an element of tentativeness. The technique of tentative interpretation merely recognizes this. In most cases the patient understands this already, for he knows from personal experience in the general treatment of himself and his acquaintances that the best of medical, and nonmedical, diagnosticians err at times and that the most skillful therapist occasionally make mistakes. In our experience most patients respond positively rather than negatively to tentative interpretations.

Finally, it may be objected that a tentative interpretation does not have the éclat, the sudden burst of insight, that a declarative interpretation has. This often is not true. A tentative interpretation sometimes finds the patient ready for it and able to assimilate it at once; as a rule, however, insight as a result of it comes slowly, in bits, over a long period of time. Furthermore, it may be debated whether sudden bursts of insight are preferable to slowly accumulating ones.

\section{REFERENCES}

1. Basch MF. Practicing psychotherapy: a casebook. New York: Basic Books 1992, p 27-56.

2. Budman S H, Hoyt MF, Friedman S. The first session in brief psychotherapy. New York: Guilford Press $1992, p$ 110-168.

3. Cavaley RH. Psychiatry is more than a science. Br J Psychiatry 1993, 162: 154-160.

4. Chapman AH. The treatment techniques of Harry Stack Sullivan. New York: Brunner/Mazel 1978, p 80-95.

5. Chapman AH, Vieira e Silva D. Base para uma psiquiatria científica. Arq Neuropsiquiatr 1980, 38:76-80.

6. Chapman A H, Chapman MCM. Harry Stack Sullivan's concepts of personality development and psychiatric illness. New York: Brunner/Mazel 1980, pp 45-56, 90-103, 176-191.

7. Frank JD. Persuasion and healing. Baltimore: Johns Hopkins University Press 1973, p 222-234.

8. Havens L L. Participant observation. New York: Jason Aronson 1976, p 93-114. 